Of the complications which have supervened, bronchitis has on three occasions caused some anxiety; eczema genitale has been present from the outset, and urticaria occurred once. But I wish to draw attention to the treatment. The diet was restricted from the first, and one consisting principally of nitrogenous material was ordered, with green vegetables and gluten bread. Unfortunately it was found impossible to keep the child on this alone ; a little white bread was subsequently given daily, although this was restricted as far as the mother's feelings would allow her. Observations on the amount of sugar passed would be valueless if the diet was changed from day to day ; but, although the diet was not restricted as much as one could wish, it remained fairly constant, so that variations in the amount of sugar passed may be regarded as bearing a direct relation to the medicinal treatment adopted. This case has been specially adapted for making observations, as it has run a steady, chronic course. In diseases which have an invariable tendency downward, such as diabetes in children, any variation is usually attributed to the treatment. All observations of a lengthy character hitherto made as to the value of drugs in diabetes have been made on adults. There is at least one fact emphasised, and that is that the true index as to the state of the child has been rather the general appearance, its activity, and condition of nutrition than the exact amount of sugar in the urine. And one fact as to opium : whilst it had no effect in checking the amount of sugar passed, it never had any soporific effect. When the child first came for treatment, it being only four years of age, a quartergrain of opium was given four times a day in the form of a pill, which the child took well; the opium was subsequently pushed, and in November, 1892, six grains of opium were being taken per day, and there was then no usual sleepiness and no marked contraction of the pupils, but headache was constant and severe; and for this reason, when it had reached six grains per day it was discontinued. In the case of codein eight grains were taken without any soporific effect being observed. Fver since Professor Fraser's publication in Jantary, 1889, there has been doubt as to the alleged superiority of codein to opium in diabetes. Observations have been made on this case for three years, but for nine months they have been of a detailed character, in which the amount of sugar passed has been at intervals of two or three days carefully made and recorded, but it cannot be said that the result has been of so definite a character as one could wish for ; neither opium nor codein materially reduced the amount of sugar, although these substances were pushed to an enormous extent, considering the age of the patient.

I will not repeat all the details of the observations made, but be content with a brief summary. In order that the value of codein might appear apart from any effect due to previous treatment during the month of July, 1892, and the first ten days of August, no treatment whatever was ordered, with the exception of moderate restriction in diet; then on Aug. 11th a quarter of a grain of codein was given four times a day and continued till Aug. 27th, when it was increased to two grains per day. On Sept. 11th this was increased to four grains per day, on the 21 st to five grains, and on the 28th to six grains per day, till on Oct. 13th eight grains were given daily, and this was continued till the 20th. When the dose had reached eight grains it was considered unwise to increase it, especially as no material benefit had been experienced, although, on the other hand, no bad effect had been produced, the greatest inconvenience being severe headache. The average amount of sugar passed whilst one grain was given was 45.99 parts per 1000; when four grains were given daily this amount had been reduced to an average of 35.91 parts per 1000 ; when this amount was increased no corresponding diminution in the amount of sugar took place. Then an interval of seven days was allowed, during which no medical treatment was pursued. On Oct. 27th one grain of opium was given twice a day, increased to three times a day on Nov. 3rd, to four times a day on Nov. 9th, to five grains daily on Nov. 16th, and to six grains per day on Nov. 23rd. The result of the opinm treatment was that the child appeared better in itself, being more cheerful, but not at all sleepy, as one would have expected, but the headache became severe, and the amount of sugar increased.

The result of the comparison of the two drugs, codein and opium, in this case tends to favour the view that the former is not less potent than opium in reducing the amount of sugar passed in diabetes of children. It is singular that such quantities of these drugs should have no soporific effect in a child of this age; but, in order to avoid any fallacy arising from the use of opium defective in quality, in the second series of observations made in April last the opium was obtained from a different source, but with a similar result.

In the beginning of the present year some cases of diabotes were reported in the medical journals, with the result of treatment by the pancreatic juice. These reports were not of a conclusive character, but the ira provement observed in the general condition of some of the cases seemed to favour a further trial of this treatment. From Dec. 31st, 1892, till Jan. 25th, 1893, no medicinal treatment was pnrsued in my case. From Jan. 26 th to 28 th the pancreas of the sheep, after being boiled, was given to the child with the liquor in which it had been boiled; about six ounces were given per day, but on the 28 th it was discontinued because it became so nauseous to the child, making it romit. On Feb. 1st liquor pancreaticus was commenced and continued till the 16th. Subsequently 1 tried a new preparation consisting of bile and pancreatic secretion (liquor pancrobilin). The effect has been to corroborate the statements of previous observers ; the patient appeared to improve in health, she seemed brighter, the thirst was not so great, and the amount of urine passed was less, but there was no corresponding diminution in the quantity of sugar fassed; it, in fact, increased from 68.96 to 100 parts per 1000 . At no time did the patient pass so much sugar as she did under the pancreatic treatment.

To conclude, I think the very unusal history of the above case will sufficiently vindicate its publication, and I only have to add that since ceasing to treat the case with drugs in A pril, 1893 , the condition of the patient has remained in statu quo. Leicester.

\section{ROTATION OF THE SPLEEN; REMOVAL; RECOVERY.}

By EDWARD MALINS, M.D. WDIN., M.R.C.P.LOND, OBSTETRIC PHYSICIAN TO THE GENERAL HOSPITL, BImATMGEAM.

IN the early part of the year I recorded briefly in THe LANCET ${ }^{1}$ a case of Axial Rotation of the Spleen and noted the fact of its removal with success. The subsequent history is sufficiently interesting to warrant some forther details being published. The patient, a small, spare worman thirty years of age, was admitted into the General Hospital, Birmingham, on Dec. 31st, 1893, with the following history. She had been married ten years, and had had fons children and no miscarriages; her last labour was sixteen months ago. Menstruation was normal. She had a marked scar on the forehead, stated to be due to an abscess after a fall eight years ago. On the left tibia there was also an irregular depressed cicatrix, which, she stated, was the remains of a "lump" which gathered and left a sore place six years ago. The family history was negative. Some months previously she first noticed a swelling in the left side below the ribs; it was movable and painless. It increased in size rapidly, spread over the middle towards the right sides and lower down, but it did not give rise to any special inconvenience. On Dec. 25th, without any previous effort or injury, she was seized with severe pain in the abdomen, vomiting, and prostration, which continued with litile or no relief until her admission to hospital. On examination the abdomen was found to be distended, being very tender to the touch; she complained of much pain all over it. Occupying the lower part of the abdomen, chiefly on the leit side, was a dense, firm swelling with a uniform surface, very sensitive to palpation; it could be traced above the umbilicus and upwards to the left side, but from the distension of the abdomen could not be marked out in this direction. Below, it passed into the pelvis, pushing the uterus backwards; the edge could be felt through the vaginal roof on the left. It appeared to be movable as far as manipulation allowed, and on the right side a margin could be made out. The temperature was $100^{\circ} \mathrm{F}$. and the pulse 110 ; the expression was anxions and the tongue was dry, but there was no albumen in the urine. On Jan. 2nd, 1894, an incision was made in the miảdle line, when the tumour was found to be the spleen enlarged, purple-coloured, tense, and rotated for half a revolution upon 
its axis. The pedicle was nearly an inch in thickness, the veins being thrombosed and firm. On attempting to restore the position the twist resumed its abnormal state; there seenued to be a risk of breaking it off. Two thin, strong, prepared silk ligatures were placed round the pedicle without transfixion, and the spleen was cut away. Some omental adhesions were first tied and separated. The abdominal cavity was carefully cleared of about six ounces of red, serons flaid; the wound was closed with silk sutures, and antiseptic $d$ ressings were applied. On the following day the temperature was $988^{\circ}$, and the pulse was 100 . On the fourth day the patient said that she had passed a better night than she had alone for many months past. On the sixth day the pulse was 82 , the temperature remaining normal. She made an uneventful recovery and left the hospital on Jan. 25tb, remarking that she felt much better without her spleen than with it.

Dr. Douglas Stanley, pathologist to the hospital, has kindly furnished a report of his examinations as follows : "The spleen, which weighed $21 \mathrm{~b}$. $5 \mathrm{oz}$., was much enlarged, firm, and of a dark colour. The increase in its size was general, so that there was not much alteration in shape, but the notches were very indistinct. The capsule was much thickened. There was a well-marked twist of the vessels, \&c., forming the pedicle; it was found that complete thrombosis bad occurred so as to make them impervious. Microscopic examination of the spleen showed great engorgement with red corpuscles, the sinuses and meshes of the reticulum being everywhere crowded with them. The fibrous framework and capsule were much thickened. No abnormal elements conld be detected. The blood was examined on several occasions; the first estimation was on Jan. 4th, when the numbers per cubic millimetre were : red blood corpuscles, 4,900,000; white blood corpuscles, 10,000 . There was little alteration in these figures for some days, and the hromoglobin likewise maintained a fairly normal reading. On Jan. 17th there were per cubic raillimetre : red blood corpuscles, $4,600,000$; white blood corpuscles, 15,000-showing that the numerical value of the blood seemed to be practically normal. The patient came to the hospital on March 30th, when the following estimation was made : red blood corpuscles, 5,050,000; white blood corpuscles, 30,000 ; hæmoglobin, 50 per cent. There was nothing apecial to be noted in the character of the corpuscles. On the 28th of April, however, another examina. tion was made, when the same increase in the number of white corpuscles was again found, bejng 30,000 per cubic millimetre, with $4,840,000$ red cells. The most remarkable point was the presence in the blood of fairly considerable numbers of large white nucleated corpuscles, varying in diameter from $30 \mu$ to $50 \mu$, in which were contained several red blood cells, in some, twenty or more. In individual ones the red corpuscles appeared to be undergoing a process of disintegration, while small masses of blood pigment could be observed in those where the change was most marked. The last examination was made on May 23rd, when a reduction in the number of red cells was noted, these having fallen to $3,300,000$ per cubic millimetre. there being a still more marked number of leucocytes, 50,000 white corpuscles per cubic millimetre.'

Birmingliate.

\section{THE NATURE AND TREATMENT OF ASPHYXIA NEONATORUM.}

BY ALEXANDER MORISON, M.D., F.R.C.P. EDIN., M.R.C.P. LOND.,

PHXSICTAN TO OUT-PATIENTS, GREAT NORTHERN CEXTRAL HOSPITAI; PHXSICTAN TO THE ST. MARYLEBONE GENERAI DISPENSARY.

Classification.--We have now to consider an important clinical distinction in the stages of this condition, which has for long been impressed upon observers by experience, and probably upon many who, though struck by the notable difference in the general appearance of these cases, have not investigated in any exhaustive manner the anatomical and physiological factors which underlie asphyxia neonatorum livida and pallida respectively, or the "blue," "apoplectic" or "cyanotic," and the " pale "' or " anæmic" cases of apparent death in the newly-born. Barnes divides these cases into three groups, with the first two of which we are at present mainly concerned. These are, firstly, " simple asphyxia," by which he denotes the livid variety, and which he attributes to interrupted hæmatosis or arrest of placental respiration before the establishment of lung respiration. Interrupted hæmatosis doubtless plays an important part in both varieties, but so general a cause cannot account for the fact noted by Cazeau, ${ }^{2}$ and generally admitted, that the cyanotic tint is most perceptible in the upper portion of the body, and especially in the face. This is indicative of local anatomical influences. Just as the "intermixture theory" of cyanosis from cardiac malformation has given place in great measure to the "obstructive theory," so also must the rôle of defective hæmatosis be a comparatively limited one in the production of the cyanosis met with in the first stage of asphyxia neonatorum. Barnes' second group he terms "paralytic asphyxia," or that in which respiration is prevented by incapacity of the nervous centres. In his third group he includes "atelectasis," due to imperfect development. As "atelectasis" and "apneumatosis" have much the same significance, I presume that Barnes refers in his third group to the persistent atelectasis associated with congenital local defects in the heart or lungs, otherwise the creation of this category is scarcely called for, as atelectasis may be a feature of the two preceding classes; this, however, I say with diffidence, as criticising the classification of one for whose genins I have the most profound respect. Schultze ${ }^{3}$ makes the presence or absence of muscular tonus a criterion. It is present in the livid, absent in the pale variety. These he regards as the first and second stages of one condition. The former is with justice regarded as, on the whole, the less serious, but it must be remembered that, although the primary or cyanotic stage may be that from which recovery is most easy, it is undoubtedly also that in which the prospect of recovery from the pale and more grave condition may be determined; for the lung, and possibly other organs, may be so damaged in the first stage in utero, from blood engorgement and extravasation, as to render recovery from the second stage after birth impossible. Although, therefore, the apparently dead "cyanotic" child, and the "pale" child in the same condition, may represent different stages of one kind of disorder, it does not follow that the etiological factors within the foetus are the same in both cases, and therefore the conditions underlying them may-and, I believe, do-differ. In the earlier stage the child has a more sentient central and local nervous system, more vigour, greater respiratory power, and makes more powerful efforts to breathe. It is, in short, apparently less dead. Hence it diverts the blood current more powerfully lung. wards, causing stagnation in a comparatively active afferent circulation from the mother when still attached, which the foetal heart with diminished outlets (ductus arteriosus and, less probably, foramen ovale) fails to dispose of. Thus it is that congestion with lividity is most evident in those regions in which the foetal circulation is most active, and which, it must be remembered, are in utero also usually most dependent, as the diagram in my previous article shows. In the more advanced, or pale, stage the nervous system, and with it the heart, have practically given up the struggle; respiratory effort is much feebler, if made at all, and such blood as is derived from the sluggish afferent current when the cord remains uncut, and which still circulates, finds its way unimpeded through the gaping foetal channels and orifices towards the outlet of the aortic system in the umbilical arteries, or is, in other words, more equally distributed.

Except in the case of cyanosis due to cardiac malformation, the newly born child rarely dies in the livid stage of asphyxia. As a rule it dies pale. It is known that even wellmarked cases of true cyanosis become paler after death, just as they frequently become more livid on coughing or on other interruption to respiration during life. Feebleness and death are indeed always paler than preceding conditions of greater vigour and of life; it is not remarkable, therefore, that the post-mortem appearances should be much the same in all fatal cases. Some, even of these, however, such as the lung ecchymoses, represent an ante-mortem phase of more vigorous struggle for life, and, could the child be examined anatomically in this earlier stage, stasis unrelieved through the fotal channels would be more pronounced than in the

2 Gazette Médicale de Paris, 1850, p. 318. 3 Loc. cit., p. 24. 4 THE LANCET Feb. 24th, 1894

- Walshe: Diseases of the Heart, fourth edition, p. 422. 